\title{
The optimization of vehicles recycling facility location
}

\author{
A. Merkisz-Guranowska \\ Poznan University of Technology, Poland
}

\begin{abstract}
Today the issue of the organization of end-of-life vehicle recycling network has become one of the essential elements related to the car manufacturing industry, particularly in developed economies. The formation of a recycling network should be planned and organized carefully to ensure its efficiency and resource optimization. That is why the creation of the network requires appropriate tools that will allow a proper location of the recycling network structural elements. Moreover, while designing a vehicle recycling network one needs to take many technical, organizational, legal and economic factors into account. Thanks to this, the process of developing of the network or locating new facilities will ensure maximum benefits equally for the network participants, the end-of-life vehicle owners and other stakeholders.

In this paper an example of a decision support model whose task is to optimize the location for vehicles recycling facilities has been presented. Upon determining of the system elements, its structure has been mapped providing correlations among the entities based on material flow and cost analysis. The research problem has been formulated based on the identification of the characteristics of the main facilities (return stations, dismantlers and industrial shredders) and requirements set by different stakeholders. The model description contains a system of constraints along with boundary conditions that generate a set of admissible decisions as well as the objective function that constitutes the basis for the evaluation of the proposed solutions. In the end optimization task was formulated and presented.
\end{abstract}

Keywords: recycling network, structure modelling, optimization, end-of-life vehicles. 


\section{Introduction}

In the modern world the design of end-of-life vehicle recycling network has become an indispensable element related to the advancement of the automotive industry and the functioning of transport. The necessity to design recycling networks is a result of legal requirements on one hand and economical conditions on the other. Vehicle recycling network is developing most intensely in the EU member states, Japan and the US. Almost $60 \%$ of the world automotive fleet falls in these three regions, hence the attention devoted to the treatment of end of life vehicles.

End of life vehicles are a precious source of recycled materials whose recovery gives substantial financial benefits. Any lack of action related to the proper treatment of the said vehicles results in these vehicles constituting a burden for the natural environment because they contain a variety of substances that, when reaching the soil and ground waters, contaminate them. Besides, in the EU only, each year end of life vehicles generate almost 12 million tons of waste that, if not treated, have to be accumulated at the disposal sites. The limiting of the negative impact on the natural environment was the main motivation for the directive introduced in the EU in 2000 on ELV [1]. The directive forces all member states to establish vehicle-recycling networks on their territories that would guarantee each end-user the possibility of returning his vehicle to the network and superimposes the recovery efficiency indexes.

The formation of networks requires decisions related to the location of the network entity. These decisions can be taken on the macroeconomic level when the responsibility for the creation of the network lies on the side of the government or organizations responsible for recycling networks. They can also be taken on a microeconomic level when individual business entities decide about the location in the context of an already existing network. Irrespective of who designs the recycling network and the motivation for the design the forming of the structure should not be incidental, hence the need to use optimization tools for the location of network entities.

In the further part of the paper the author will present an example optimization tool used in the process of location of entities in the redesign process of the recycling network on a given area.

\section{Literature studies}

The issues of design of an end of life vehicle recycling network are a part of a wider research area - reverse logistics. Reverse logistics can be defined as the process of planning, implementing and controlling the efficient, cost effective flow of raw materials, in-process inventory and finished goods from manufacturing, distribution or point of consumption to a point of recovery or point of proper disposal for the purpose of recapturing of the value or proper disposal $[2,3]$. 
The research areas related to the optimization of recovery logistics can be divided into the following groups:

- recovery process optimization and selection of applied methods,

- waste logistics management- direction and size of the flows among the entities of the recycling network,

- optimization of the location of the entities of recovery logistics.

The issues related to the selection of the location are a separate group of optimization tasks. The optimization of the location of a network entity in traditional logistics has received a lot of attention for many years and the reverse logistics has been a subject of investigations for a relatively short period of time. Because it is gaining in popularity, many papers have been written treating on the entities participating in the reverse logistics. The range of the investigations covers the area of municipal waste, hazardous waste, packaging, electrical and electronic equipment and waste paper or general end of life products. It is relatively seldom, judging from the scale of the problem, that the issue of optimization of location of ELV recycling network is treated in the literature. In relevant literature we can find only a few examples of research studies devoted to the design of vehicle-recycling network. The main assumptions of these works have been presented below.

Mansour and Zarei [4] have set a goal to identify the sources of costs related to the obligation imposed by the EU regulations and develop a model that would include the optimization of the end-of-life vehicle reverse logistics showing the number, location and throughput of the return stations, dismantlers and the flow statistics among the entities. What makes this model different is that the modeling of the process and the recovery is done for more than one period while most of the models described in the literature assume a single stage end-of-life product processing. The use of the multi-period model allowed incorporating the differences in the end-of-life vehicles supply between the periods and included the storage costs. As a criterion of optimization the authors adopted the minimization of costs of logistics for the vehicle manufacturers and the minimization of the material flow among the entities.

The model of optimization of the location of the entities of end-of-life vehicle recycling network in Mexico has been presented in the work by Cruz-RiverA and Ertel [5]. In this model it has been assumed that the return stations are also dismantlers, i.e. the structure of the network has been simplified. Yet, the scenarios of return station locations were shown for the return of $75 \%, 90 \%$ and $100 \%$ of the end-of-life vehicles on a given area. The basic feature that distinguishes this model is that the locations of the regional distribution centers are not selected from among the initially set potential locations but are indicated by the model.

The above-presented works are focused on designing of a separate network for the recovery logistics. Because of the differences in the new and end-of-life streams of products rarely is it proposed to connect the reverse logistics with the new vehicle distribution network. The model designed for locating of the new vehicle distribution network entities joined with the end-of-life vehicle recycling network has been presented in the work of Zarei et al. [6]. In this case the 
optimization is based on simultaneous minimization of costs of forward logistics and reverse logistics and both of the logistic systems are a unity. The objective function minimizes the costs of developing of joint distribution and return entities, the costs of developing of the dismantlers and the costs of transport of end-of-life vehicles and materials. The proposed model assumes an ELV recycling network organization that meets the assumptions of the ELV directive i.e. takes the specificity of the European member states into account.

Also Schultmann et al. [7] in network optimization set a goal to integrate reverse logistic with a traditional logistics network. The main stress in the design of the network was put on the possibility of including the flows from the reverse logistics network to the original production and distribution network. The effect was presenting of the model of location/ allocation covering at the same time the selection of the functioning location of the entities and the material flows based on the German end of life vehicle recycling network.

\section{The assumptions behind the optimization of the recycling network}

The here presented model is based on a recycling network functioning in Poland but a similar model of network organization can be seen in other EU member states i.e. Germany, Austria, Greece.

Poland as one of the EU member states was obliged to take action in the area of organization of the ELV recycling network. The significance of the problems of recycling network formation, apart from the need to unify the system infrastructure with the EU requirements, also results from the forecasts of the needs for ELV treatment (approximately one million of ELV per annum) and an insufficiently developed existing vehicle recycling network. The main problems, faced by the ELV vehicle recycling industry in Poland can be listed as follows:

- insufficient number of industrial shredders and vehicle recycling facilities that the dismantlers could collaborate with,

- high operating costs of the dismantlers related to the required station equipment,

- too high a number of dismantlers in comparison to the number of ELVs,

- the operation of 'underground economy' processing a significant number of ELVs.

On one hand we have too many entities on the dismantler level, on the other there is an insufficient number of entities that constitute further relations in the system. The main problem however is the low profitability of the whole system and the additional factor that can make the situation worse is the retraction of the government from subsidizing of the dismantling process.

The key element for the improvement of the functioning of the recycling network in Poland is to redesign the system that will allow a reduction of the total costs related to the vehicle recycling.

In Poland we currently have a three-stage recycling network, the schematics of which have been presented in figure 1. In the three-stage ELV recycling network the vehicles are either directed to the return stations or directly to the 
dismantlers. The return stations do not take any actions related to processing of the ELVs- their task is to forward the ELVs to the dismantlers. At the dismantlers parts that can be reused are retrieved and forwarded directly to the recipients. Hazardous materials (batteries, oil) and other vehicle elements that cannot be resold (glazing, tires, seats) are forwarded to the specialized material recycling facilities. A hulk is directed to the shredder where scrap metal is recovered (ferrous and non-ferrous metals). Scrap metal is forwarded to material recycling facilities and steelworks as well. Recycling facilities sell the recovered materials on the market.

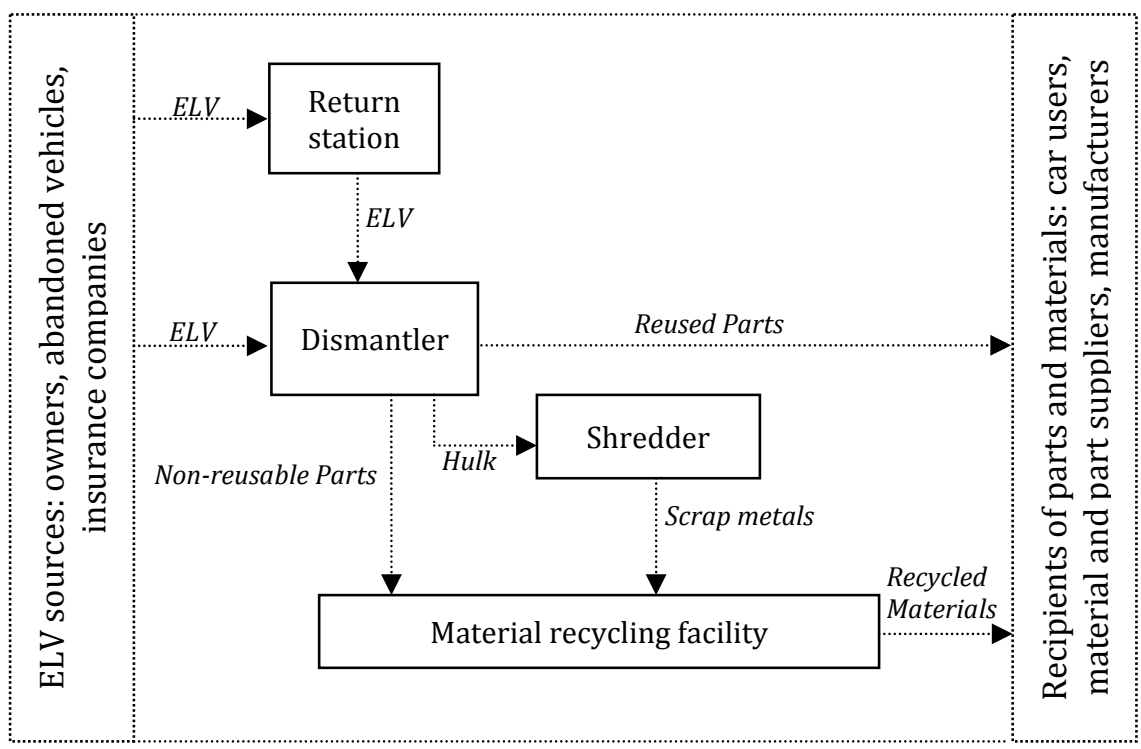

Figure 1: The participants and the flows in the recycling network.

\section{The mathematical model}

In the further part of the paper the author will present a mathematical model used for the optimization of the location of the entities of the recycling network that ensures minimization of the total costs of the network operation.

For the model construction the following assumptions have been adopted:

- For the optimization of the location the following entities have been selected: return stations $(P)$, dismantlers $(S)$ industrial shredders $(M)$.

- The sources of ELVs $(I)$ were municipalities.

- The plastic recycling facilities $(\mathrm{T})$ and non-ferrous metals recycling facilities (N) were selected for the collaboration with the dismantlers. Only those processing facilities were selected that generated the highest costs for the stations. The model did not include materials that do not generate costs related to their forwarding to the recycling facilities and for which the return 
network is sufficiently dense and does not influence the location of the dismantler (tires, batteries, used oil).

- The shredders collaborate similarly to the non-ferrous materials recycling facilities $(N)$ and additionally with the ferrous materials recycling facilities (Z).

The relations among the individual elements of the network have been presented in figure 2 and marked as follows:

- A - relation ELV source- return station,

- $\mathrm{B}$ - relation ELV source - dismantler,

- C - relation return station- dismantler,

- D - relation dismantler - industrial shredder,

- E - relation dismantler - plastic recycling facility,

- F - relation dismantler - non-ferrous metals recycling facility,

- $\mathrm{G}$ - relation industrial shredder- non-ferrous metals recycling facility,

- $\mathrm{H}$ - relation industrial shredder -ferrous metals recycling facility.

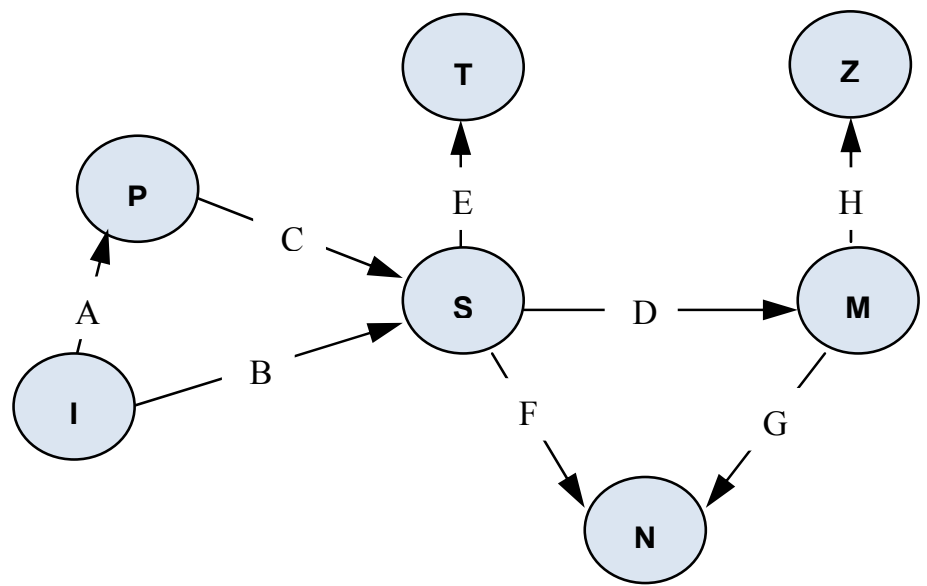

Figure 2: $\quad$ Recycling network model.

For the entities subject to optimization it was necessary to determine the costs of functioning. For the dismantlers and the industrial shredders the operating costs are composed of overheads $\left(k^{S}\right)$ and variable costs $\left(k^{Z}\right)$. The overheads reflect the expenditure for start-up and equipping of the entity (depreciation) and cover other costs generated in relation to keeping of the system ready for operation (i.e. personnel wages). The level of the overheads depends on the throughput potential of the entity $(\mu)$ but it does not depend on the actually processed mass of waste i.e. number of ELV. The unit variable cost denotes a cost of processing of a single ELV or $1 \mathrm{~kg}$ of waste; hence the total variable costs grow proportionally to the actual throughput. In the case of return stations variable costs have not been determined as these entities do not process ELVs but forward them directly to the dismantlers and their total costs equal to the 
overheads. What is more, the return stations do not have a throughput potential and overheads have the same value for all return stations.

Another important component of the total cost is the cost of transport. The costs of transport are directly proportional to the amount of flows in the individual relations and are a product of unit transport costs (varied depending on what is transported) and the distance between the entities. Additionally an overhead transport cost was included related to the initiating of a given transport.

Decision variables in models related to the redesign of the existing recycling network are binary variables determining the presence of an entity (for the value of 1) or its removal from the network (for the value of 0). Beside the variables relating to the entity locations another group of variables were identified that determine the flows (ELVs or waste) on individual relations marked with $f$.

The objective function relates to the minimization of the total network costs being the sum of the operating costs of the return stations, dismantlers, industrial shredders and the costs of transport of ELVs and waste in all the described relations. Additionally, conversion factors have been introduced of 1 ELV into individual waste elements for the dismantler and the conversion factors of processing of the hulk at the shredder input into waste at the shredder output. They determine how much waste of a given type would be forwarded to the next entity in the system. These conversions have been marked with $\chi$ with an appropriate upper index identifying the relation.

The objective function can be notated as follows:

$$
\min \left\{K^{P}+K^{S}+K^{M}+K^{A}+K^{B}+K^{C}+K^{D}+K^{E}+K^{F}+K^{G}+K^{H}\right\}
$$

where:

$$
K^{P}=k^{S P} \sum_{p=1}^{P} x_{p}^{P}
$$

$K^{P}$ reflects the collective operating costs of the return stations and $k^{S P}$ is an overhead of the return stations, and the variable of the return station location was marked $x_{p}^{P}$.

$$
K^{S}=\sum_{s=1}^{S} x_{s}^{S}\left(k^{S S}\left(\mu_{s}^{S}\right)+k^{Z S} \frac{f_{s}^{D}}{\chi^{D}}\right)
$$

$K^{S}$ reflects the collective operating costs of the dismantlers and $k^{S S}$ is an overhead of functioning depending on the station throughput potential $\left(\mu_{s}^{S}\right)$, and $k^{Z S}$ is a unit variable cost of the station multiplied by the value of the station throughput. For the simplification of the notation the throughput of a given station is determined through the stream at the output $\left(f_{s}^{D}\right)$ divided by the conversion factor of waste processing for a given relation $\chi^{\mathrm{D}}$. The selection of the location of the dismantler is determined by variable $x_{S}^{S}$.

$$
K^{M}=\sum_{m=1}^{M} x_{m}^{M}\left(k^{S M}\left(\mu_{m}^{M}\right)+k^{Z M} \frac{f_{m}^{H}}{\chi^{H}}\right)
$$


Analogically to the dismantlers the operating cost of the industrial shredders was calculated marked $K^{M}$. The symbols denote: $x_{m}^{M}$ selection of the shredder location, $k^{S M}$ overheads, $\mu_{m}^{M}$ shredder throughput potential, $k^{Z M}$ variable costs, $f_{m}^{H}$ stream at the output in relation $\mathrm{H}, \chi^{\mathrm{H}}$ waste processing conversion factor for relation $\mathrm{H}$.

$$
K^{A}=\sum_{i=1}^{I} \sum_{p=1}^{P} f_{i p}^{A}\left(d_{i p}^{A} k^{T A}+k_{0}^{T A}\right)
$$

$K^{A}$ reflects the collective costs of transport for relation $\mathrm{A}$ that are a product of the flows and the sum of transport overheads ( $k_{0}^{T A}$ converted in to a unit of mass) and the product of distance $\left(d_{i p}\right)$ between the ELVs and the return stations and the unit variable costs of transport for relation $\mathrm{A}\left(k^{T A}\right)$.

$$
K^{B}=\sum_{i=1}^{I} \sum_{s=1}^{S} f_{i s}^{B}\left(d_{i s}^{B} k^{T B}+k_{0}^{T B}\right)
$$

$K^{B}$ reflects the collective costs of transport for relation $\mathrm{B}$, where $k_{0}^{T B}$ denotes unit transport overheads for relation $\mathrm{B}, d_{i s}$ distance between the sources and the stations, $k^{T B}$ unit variable cost of transport for relation $\mathrm{B}$.

$\mathrm{K}^{\mathrm{C}}$ and $\mathrm{K}^{\mathrm{D}}$ reflect the collective costs of transport for relation $\mathrm{C}$ and the collective costs of transport for relation $\mathrm{D}$, calculated analogically to relations $\mathrm{B}$ and $\mathrm{C}$.

$$
\begin{aligned}
K^{C} & =\sum_{p=1}^{P} f_{p}^{C}\left(d_{p}^{C} k^{T C}+k_{0}^{T C}\right) \\
K^{D} & =\sum_{s=1}^{S} f_{s}^{D}\left(d_{s}^{D} k^{T D}+k_{0}^{T D}\right)
\end{aligned}
$$

The cost of transport calculation formula for the outstanding relations differs from the previous ones in that they must include the throughput potential of the dismantler or industrial shredder because the value of the throughput influences the extent of transport, hence it influences the value of the unit overheads and variable costs. Below, the collective costs of transport for relation E eqn (9), for relation $\mathrm{F}$ eqn (10), for relation $\mathrm{G}$ eqn (11) and for relation $\mathrm{F}$ eqn (12) have been presented.

$$
\begin{aligned}
K^{E} & =\sum_{s=1}^{S} f_{s}^{E}\left(d_{s}^{E} k^{T E}\left(\mu_{s}^{S}\right)+k_{0}^{T E}\left(\mu_{s}^{S}\right)\right) \\
K^{F} & =\sum_{s=1}^{S} f_{s}^{F}\left(d_{s}^{F} k^{T F}\left(\mu_{s}^{S}\right)+k_{0}^{T F}\left(\mu_{s}^{S}\right)\right) \\
K^{G} & =\sum_{m=1}^{M} f_{m}^{G}\left(d_{m}^{G} k^{T G}\left(\mu_{m}^{M}\right)+k_{0}^{T G}\left(\mu_{m}^{M}\right)\right)
\end{aligned}
$$




$$
K^{H}=\sum_{m=1}^{M} f_{m}^{H}\left(d_{m}^{H} k^{T H}\left(\mu_{m}^{M}\right)+k_{0}^{T H}\left(\mu_{m}^{M}\right)\right)
$$

Apart from constructing the objective function it is necessary to introduce limitations. The first equation (13) is to guarantee the collection of all ELVs from the sources. The other limitations eqns (14)-(18) are limitations related to the flows according to which the sum of flows at the entity input must equal that at the output using the conversion factor.

$$
\begin{gathered}
\sum_{i=1}^{I} f_{i p}^{A}=f_{p}^{C} ; \quad \forall p=1 \ldots P \\
\sum_{i=1}^{I} f_{i s}^{B}+\sum_{p \in \Delta_{s}^{C}} f_{p}^{C}=\frac{f_{s}^{D}}{\chi^{D}} ; \forall s=1 \ldots S \\
\sum_{i=1}^{I} f_{i s}^{B}+\sum_{p \in \Delta_{s}^{C}} f_{p}^{C}=\frac{f_{s}^{E}}{\chi^{E}} ; \forall s=1 \ldots S \\
\sum_{i=1}^{I} f_{i s}^{B}+\sum_{p \in \Delta_{s}^{C}} f_{p}^{C}=\frac{f_{s}^{F}}{\chi^{F}} ; \forall s=1 \ldots S \\
\sum_{s \in \Delta_{m}^{D}} f_{s}^{D}=\frac{f_{m}^{G}}{\chi^{G}} ; \quad \forall m=1 \ldots M \\
\sum_{s \in \Delta_{m}^{D}} f_{s}^{D}=\frac{f_{m}^{H}}{\chi^{H}} ; \quad \forall m=1 \ldots M
\end{gathered}
$$

Then, limitations were introduced related to the throughput potential eqns (19)-(23). The flows to the dismantlers, industrial shredders and material recycling facilities cannot exceed the throughput potential of these entities. The exception is the return stations that can collect any number of ELVs; for them the only limitation is the potential of the dismantlers with which they are in collaboration.

$$
\begin{gathered}
\sum_{i=1}^{I} f_{i s}^{B}+\sum_{p \in \Delta_{s}^{C}} f_{p}^{C} \leq \mu_{s}^{S} ; \quad \forall s=1 \ldots S \\
\sum_{s \in \Delta_{m}^{D}} f_{s}^{D} \leq \mu_{m}^{M} ; \quad \forall m=1 \ldots M \\
\sum_{s \in \Delta_{t}^{E}} f_{s}^{E} \leq \mu_{t}^{T} ; \quad \forall t=1 \ldots T
\end{gathered}
$$




$$
\begin{gathered}
\sum_{s \in \Delta_{n}^{F}} f_{s}^{F}+\sum_{m \in \Delta_{n}^{G}} f_{m}^{G} \leq \mu_{n}^{N} ; \forall n=1 \ldots N \\
\sum_{m \in \Delta_{z}^{H}} f_{m}^{H} \leq \mu_{z}^{Z} ; \quad \forall z=1 \ldots Z
\end{gathered}
$$

Another limitation eqn (24) that was introduced is related to the accessibility of the return stations and/or dismantlers from the point of view of the ELV owner. It has been assumed that the owner must have access to the station or dismantler within a certain distance that cannot be exceeded $\left(\mathrm{d}^{\max }\right)$.

$$
\underset{p}{\exists}:\left(x_{p}^{P}=1 \wedge d_{i p}^{A} \leq d^{\max }\right) \vee \underset{s}{\exists}:\left(x_{s}^{S}=1 \wedge d_{i s}^{B} \leq d^{\max }\right) ; \forall i=1 \ldots I
$$

Additionally we need to include in the limitation the condition that the variables determining the flow size are positive real numbers and the values of the flows for relations $\mathrm{A}, \mathrm{B}$ and $\mathrm{C}$ must be integers as they denote the number of ELVs. Besides, the location variables are binary numbers.

\section{The results of an example optimization task}

Due to the scale of the problem and the number of variables for the solution of the optimization tasks the genetic algorithms were used with the help of Java software.

The model tests were performed on one of the sixteen voivodeships of Poland- the voivodeship of Wielkopolska. In this Province there are currently 5 return stations, 84 dismantlers and 1 industrial shredder. In the optimization task it has been assumed that the dismantlers can collaborate with the industrial shredders and material recycling facilities in different locations in Poland as it actually happens in reality. Similarly, the industrial shredders can collaborate with recycling facilities located in any part of the country.

Summarizing the solutions proposed by the software we could draw the following conclusions:

- Out of the existing entities in Wielkopolska the software selected 1 return station (20\% of the existing ones) and 38 dismantlers (45\% of the existing ones) and the maximum distance between the source and the ELV collection point was $50 \mathrm{~km}$.

- The hulk from the dismantler must go to the closest industrial shredder located in the region under analysis or another region.

- The majority of the costs of the whole system are the operating costs of the entities $(93 \%$ of the total costs) while the transport costs have a $7 \%$ share in the total costs.

- Almost half of the transport costs is the costs of transporting of the hulk from the dismantlers to the industrial shredders and out of the total operating costs the costs of industrial shredders constitute 54\%, and the dismantlers $45 \%$. 
The results of the task indicate that the transport of waste does not play a significant role in the total costs of functioning of the system. What is important is that the use of all entities be optimized i.e. in the network there should be as few entities as possible with their throughput potential maximized.

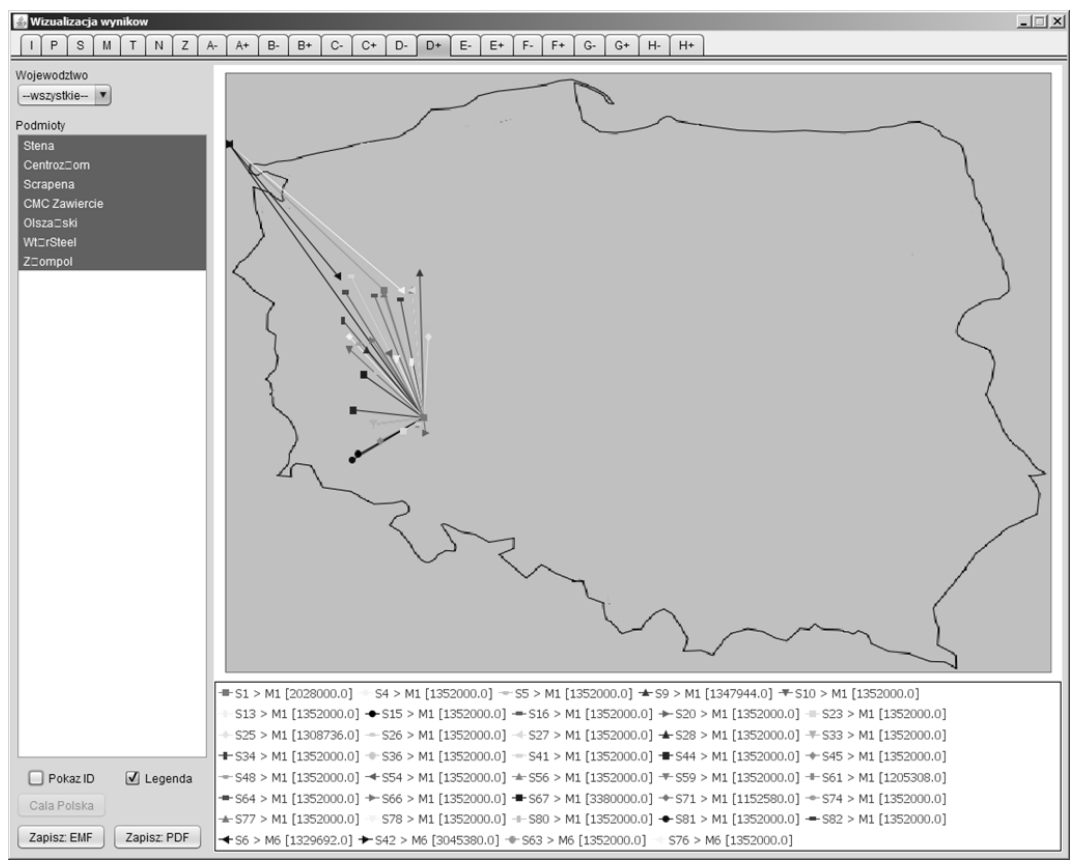

Figure 3: Visualization of the results for flow D.

\section{Conclusions}

The decision related to the recycling network entity location should take into account as many factors as possible (technical, economic, environmental and legal). If so, the formation of a selected fragment of the network e.g. in the context of its extension and location of new entities shall ensure maximization of benefits from both the point of view of the network participant and that of the vehicle owners not to mention other stakeholders.

The here described example application of the methods of optimization of the location of recycling network entities is a useful tool for the evaluation of the existing network and for the determining of the locations of entities when creating a new network and extending the existing network by new entities. As an objective function the minimization of costs has been assumed as in market economies the profit account is of key importance. The model has so far been tested on selected areas only but the obtained results allow its usage for the optimization in a wider context i.e. countrywide. 


\section{Acknowledgements}

This scientific work has been financed from the government scientific grant for the years 2010-2012 classified as a research project. Project number N N509 601839. Project title: The methodology of formation of transport and logistics networks in selected areas. Project manager: Marianna Jacyna.

\section{References}

[1] Directive 2000/53/EC of the European Parliament and the Council of 18 September 2000 on end-of-life vehicles, Official Journal of the European Communities, no 269, 2000.

[2] De Brito, M.P. \& Dekker, R., Reverse logistics - a framework, Econometric Institute Report, EI 2002-38, pp.1-19, 2002.

[3] Rogers, D.S. \& Tibben-Lembke, R.S., Going backwards: reverse logistics trends and practices, Reverse Logistics Executive Council: Pittsburgh, pp.2-3, 1999.

[4] Mansour, S. \& Zarei, M., A multi period reverse logistics optimization model for end-of-life vehicles recovery based on EU Directive. International Journal of Computer Integrated Manufacturing, 21(7), pp.764-777, 2008.

[5] Cruz-Rivera, R. \& Ertel, J., Reverse logistics network design for the collection of end-of-life vehicles in Mexico. European Journal of Operational Research, 196(3), pp.930-939, 2009.

[6] Zarei, M., Mansour, S., Husseinzadeh Kashan, A. \& Karimi, B., Designing a Reverse Logistics Network for End-of-Life Vehicles Recovery. Mathematical Problems in Engineering, 10.1155(2010), pp.1-16, 2010.

[7] Schultmann, F., Zumkeller, M. \& Rentz, O., Modeling reverse logistic tasks within closed-loop supply chains: an example from the automotive industry. European Journal of Operational Research, 171(3), pp.1033-1050, 2006. 